\title{
Expression of a Y-located human proto-oncogene TSPY in a transgenic mouse model of prostate
}

\section{cancer}

Tatsuo Kido ${ }^{1}$, Stephanie Schubert ${ }^{2}$, Shingo Hatakeyama ${ }^{3}$, Chikara Ohyama ${ }^{3}$, Jörg Schmidtke ${ }^{2}$ and Yun-Fai Chris Lau ${ }^{1 *}$

\begin{abstract}
Background: The human TSPY is the putative gene for the gonadoblastoma locus on the Y chromosome (GBY). Various molecular, pathological and transgenic mouse studies suggest that TSPY is a Y-located proto-oncogene contributing to the initiation/progression in human cancers, including germ cell tumors and various somatic cancers, such as prostate and liver cancer, and melanoma. The TgTSPY9 transgenic mouse line harbors a 8.2-kb human TSPY structural gene, which is tandemly integrated in the mouse $Y$ chromosome, and expressed in a similar pattern as that of the endogenous gene in the human genome. This mouse model of human TSPY gene offers an opportunity to examine its behavior and potential contribution in various mouse models of human diseases, such as human cancers. We had investigated the expression of such TSPY-transgene in the LADY mouse model of prostate cancer, harboring a SV40 T antigen gene directed by a rat probasin promoter; and compared the expression pattern with those of endogenous TSPY gene and biomarkers in human prostate cancer specimens.
\end{abstract}

Results: By introducing the Y-located TSPY-transgene to the LADY mice, we had examined the expression pattern of the human TSPY during prostatic oncogenesis in this mouse model of prostate cancer. Our results showed that the TSPY-transgene was activated in selected areas of the hypercellular stroma but not in the intraepithelial cells/ neoplasia in the prostates of TgTSPY9/LADY mice. Using a specific biomarker, FOXA1, for epithelial cells, we demonstrated that TSPY-positive cells proliferated exclusively in the cancerous stroma in the LADY model at late stages of tumorigenesis. In contrast, in the human situation, TSPY was predominantly co-expressed with FOXA1 in the epithelial cells of PIN lesions and FOXA1 and another cancer biomarker, AMACR, in the adenocarcinoma cells in clinical prostate cancer samples of various degrees of malignancy.

Conclusions: Our data show that human TSPY could be abnormally activated during prostatic oncogenesis, and could possibly contribute to the heterogeneity of prostate cancer. The differential expression patterns of the human TSPY between the LADY mouse model and clinical prostate cancer suggest potential limitations of current mouse models for studies of either TSPY behavior in diseased conditions or prostate cancer development.

Keywords: Prostate cancer, Y-chromosome, Proto-oncogene, Transgenic mouse models, TSPY

\footnotetext{
* Correspondence: chris.lau@ucsf.edu

'Laboratory of Cell and Developmental Genetics, Department of Medicine, VA Medical Center \& Institute for Human Genetics, University of California, 4150 Clement Street, San Francisco, CA, USA

Full list of author information is available at the end of the article
} 


\section{Background}

Prostate cancer is one of the most frequently diagnosed cancers among men. More than 200,000 new cases are diagnosed each year, and more than 30,000 people die from prostate cancer in United States in 2011 (report of National Cancer Institute, United States) [1]. The etiology of prostate cancer is currently uncertain, and might follow a gradual transformation of normal prostate epithelium to prostatic intraepithelial neoplasia (PIN), and to locally invasive carcinoma and metastatic disease [2,3]. Prostate cancer initiation, development and progression are complex processes, involving multiple environmental and genetic risk factors and co-carcinogenic processes between epithelia and stroma of the prostate at different stages [4-8]. Since prostate cancer is a man-specific cancer, the contribution of genes on the male-only $\mathrm{Y}$ chromosome have been suspected, but remains controversial due to contradictory observations on the gain and loss of this chromosome in samples of numerous tumor types [9-13]. The complete sequencing of the human genome [14], particularly the Y chromosome [15], has provided significant information on the genetic content of the human $Y$ chromosome; thereby providing an opportunity to evaluate independently the various genes on this male-specific portion of the human genome.

Among the genes on the human Y chromosome, the testis-specific protein Y-encoded (TSPY) gene represents the most likely gene potentially contributing to the complex etiology of prostate cancer [16]. TSPY is a repeat gene, mapped to the critical region within the gonadoblastoma locus on the human Y-chromosome (GBY), which serves a normal function in the testis, but could predispose the dysgenetic gonads of patients of disorders of sexual development (DSD) to develop gonadoblastoma [17-21]. Indeed, TSPY is expressed in normal germ cells, and abundantly and frequently expressed in various types of germ cell tumors such as gonadoblastoma, carcinoma in situ/intratubular germ cell neoplasia unclassified (CIS/ ITGCNU), and seminoma [20-24]. Importantly, it is also expressed in various types of somatic cancer, including prostate cancer, hepatocellular carcinoma, and melanoma [25-28]. Hence, TSPY is considered as one of cancer/testis antigens as a potential candidate in vaccine strategy for immunotherapy in cancer patients [26]. TSPY interacts with the type B cyclins and enhances the cyclin-B/CDK1 activity [29]. It exhibits oncogenic properties when transfected to NIH3T3 cells [30]. Further, TSPY also interacts with various regulatory proteins, such as translation elongation factor EEF1A [31], and promotes cell growth and proliferation associated with cancer development. Hence, understanding its expression patterns could aid the development of diagnostic and therapeutic strategies in medical management of various cancers affected by this Y-located proto-oncogene.
Various mouse models of prostate cancer have been generated to investigate the susceptibility, initiation, progression and pharmacology of the disease [32-34]. The LADY (also termed as LPB-Tag) transgenic mouse line is one of these mouse models. It harbors a SV40 large T antigen (Tag) oncogene directed by a $12-\mathrm{kb}$ rat probasin promoter, which is expressed at high levels in the prostates of the host animals [35]. The LADY mice develop epithelium dysplasia, carcinoma-in-situ and adenocarcinoma in their prostates, similar to human prostate cancer [35]. The LADY model consists of several distinct transgenic mouse strains with different transgene integration sites. The $12 \mathrm{~T}-7 \mathrm{f}$ LADY is a fast disease-developing strain, and develops complex mouse prostatic intraepithelial neoplasia (mPIN) with hypercellular stroma by 20 weeks of age [36,37].

Transgenic modeling of TSPY in oncogenesis has been difficult. Although it is evolutionarily conserved on the $\mathrm{Y}$ chromosome among various mammalian species including apes and bovine [38,39], the mouse Tspy is a nonfunctional single-copy gene [40,41]. Transgenic mice harboring a human TSPY gene on their autosome(s) are difficult to maintain as transgenic mouse lines, potentially caused by its inappropriate expression and disruptive effects on the reproductive system or embryonic development of the host animals [42]. Recently, a transgenic mouse line, designated as TgTSPY9 harboring the human TSPY gene on the mouse Y-chromosome, has been established [43]. The TgTSPY9 mice harbor an $8.2-\mathrm{kb}$ genomic fragment derived from the human Y chromosome, containing the 2.8-kb TSPY transcriptional unit flanked by $2.95-\mathrm{kb}$ promoter and $2.45-\mathrm{kb} 3$ ' sequences. The $8.2-\mathrm{kb}$ TSPY-transgene is integrated tandemly about 50 copies on the $\mathrm{Y}$ chromosome of the host genome. The organization of the TSPY-transgene on the mouse Y chromosome resembles that of the endogenous TSPY gene in the human genome, which is tandemly repeated $\sim 20-60$ times on the Y chromosome. Significantly the TSPY-transgene is specifically expressed in pre-spermatogonial cells in embryonic testis and spermatogonial and prophase I germ cells in adult testis, while little or no expression is detected in other somatic tissues, including non-cancerous prostate $[42,43]$, similar to the expression pattern observed for the endogenous TSPY gene in humans $[42,44]$. Hence, by integrating onto the host Y chromosome, the TSPY-transgene is properly regulated as the endogenous gene in the human genome, thereby establishing the TgTSPY9 transgenic line as a suitable mouse model for the human TSPY gene in studies, designed to determine its functions in various biological and experimental systems.

In the present study, we have explored the potential involvement of TSPY in the oncogenic processes of the LADY transgenic mouse model of prostate cancer. Our results suggest that TSPY could be ectopically activated 
and expressed in the oncogenic process(es) in this model of prostate cancer. TSPY expression parallels those of other biomarkers, but its pattern could be different from those observed in clinical specimens of prostate cancer patients, suggesting the potential heterogeneity of oncogenic processes in both the LADY model and human prostate cancer.

\section{Results}

The human TSPY-transgene was expressed in the hypercellular stroma of TgTSPY9/LADY mouse prostate

The LADY and TgTSPY9 mice were originally maintained on CD1 and NMRI background respectively [35,43]. Since tumor development in mouse model is frequently affected by genetic background [45-47], we first analyzed the prostatic tumor development of LADY mice on CD1/NMRI F1 hybrid genetic background. Prostatic enlargement was observed at 12 weeks of age and the tumor size reached to $\sim 2 \mathrm{~cm}$ in diameter at 19 weeks, an experimental endpoint in our animal protocol. Both mouse prostatic intraepithelial neoplasia (mPIN) and hypercellular stroma and were observed in LADY mice in CD1 and CD1/NMRI background while glands were surrounded by normal appearing fibromuscular stroma in non-transgenic CD1 and CD1/NMRI F1 mouse prostate. These preliminary observations suggest that the prostatic oncogenic processes in the CD1/NMRI background were similar as those initially described in CD1 background for the LADY model of prostate cancer $[35,36]$.

To explore the potential role of the TSPY-transgene in the LADY model of prostate cancer, we crossed TgTSPY9/NMRI male mice and LADY/CD1 heterozygous female mice, and analyzed the $\mathrm{F} 1$ generation male offspring at various ages. At 12 weeks of age, small but pronounced hypercellular stroma was frequently observed in addition to the progressive expansion of atypical epithelium in the prostates of TgTSPY9/LADY mice (Figure 1G and $\mathrm{H}$ ). Immunofluorescence analysis demonstrated that large $\mathrm{T}$ antigen and Ki67, a cell proliferative marker, were expressed in the majority of cells in both epithelial and stromal cells, as observed in LADY/NMRI mice (Figure 1A-C and I). The TSPY-transgene product was locally expressed in clusters of cells in the hypercellular stroma regions (Figure 1D-F and J-L) but not the adjacent tissues.

At 19 weeks of age, both Tag and Ki67 were expressed in the majority of prostatic cells and the enlarged hypercellular stroma (Figure 2A, G-L), while the clusters of TgTSPY-positive cells expanded further with the hypercellular stroma (Figure 2C and F), but not any mPIN lesions. In contrast, no hyperplasia was observed and no obvious TgTSPY-positive cell was detected by immunofluorescence in the prostate of a single-transgenic TgTSPY9/ NMRI mouse even at 16 month of age (Figure 2D-E). Such expression pattern of the TSPY-transgene in LADY mice was different from that of the endogenous human TSPY in clinical prostate cancer samples [27,28]. These observations suggested that the behavior of TSPYtransgene in the TgTSPY9/LADY mice is likely to be different from that of human TSPY in prostate cancer.

\section{TSPY and FOXA1 are co-expressed in the same tumor cells in human prostate cancer, but not in those of the LADY model of prostate cancer}

The preferential location of the TSPY-transgene product in the hyperplastic stromal cells was somewhat different from our previous observations in clinical and latent prostate cancer specimens, in which the TSPY protein were mostly localized in the epithelial tumor cells $[27,28]$. To confirm such differential cytological locations of TSPY in both clinical samples and LADY model of prostate cancer, we have examined the TSPY expression with reference to the forkhead class DNA-binding protein A1 (FOXA1) biomarker, which is preferentially expressed in prostatic epithelial cells and play crucial roles in prostate cancer initiation and development in both human specimens and mouse models [48-50]. In human clinical prostate cancer specimens, TSPY was predominantly detected in the epithelial tumor cells, which were also positive for the tumor biomarker, alpha-methylacyl-CoA racemase (AMACR) [28]. TSPY was strongly expressed in adenocarcinoma cells positive for AMACR (Figure 3A-D). In the adjacent tissue sections, nuclei of those TSPY-positive adenocarcinoma cells were also positively stained by antiFOXA1 (Figure 3E-F). Further, both TSPY and FOXA1 proteins were co-expressed and co-localized in the same hyperplastic epithelial cells of PIN lesions (Figure 3G-J), suggesting that TSPY could exacerbate the oncogenic properties of FOXA1 and other cancer-promoting biomarkers in prostatic epithelial and tumor cells during cancer development and progression.

To further investigate the distribution of TSPY-transgene expression in TgTSPY9/LADY mice, we performed double immunofluorescence analyses of TSPY and Foxa1 endogenous gene products in the prostates of TgTSPY9/ LADY bi-transgenic and TgTSPY9/CD1 single-transgenic mice at 14 weeks and 19 weeks of age. At both ages, mouse Foxa1 was predominantly expressed in the nuclei of atypical epithelium in TgTSPY9/LADY mice and those of normal epithelial cells in the single-transgenic TgTSPY9/CD1 mice (representative images at 14 weeks of age in Figure $4 \mathrm{~B}$ and $\mathrm{F}$ respectively). In contrast, the TSPY-transgene was expressed in hyperplastic stromal cells in TgTSPY9/LADY mice, and no overlap in the respective immunofluorescence staining between the human TSPY transgene and the mouse Foxa1 endogenous gene products was observed in the merged images (Figure 4C-D). In addition, no obvious TgTSPY-positive cells were detected in the TgTSPY9/CD1 mouse prostate 

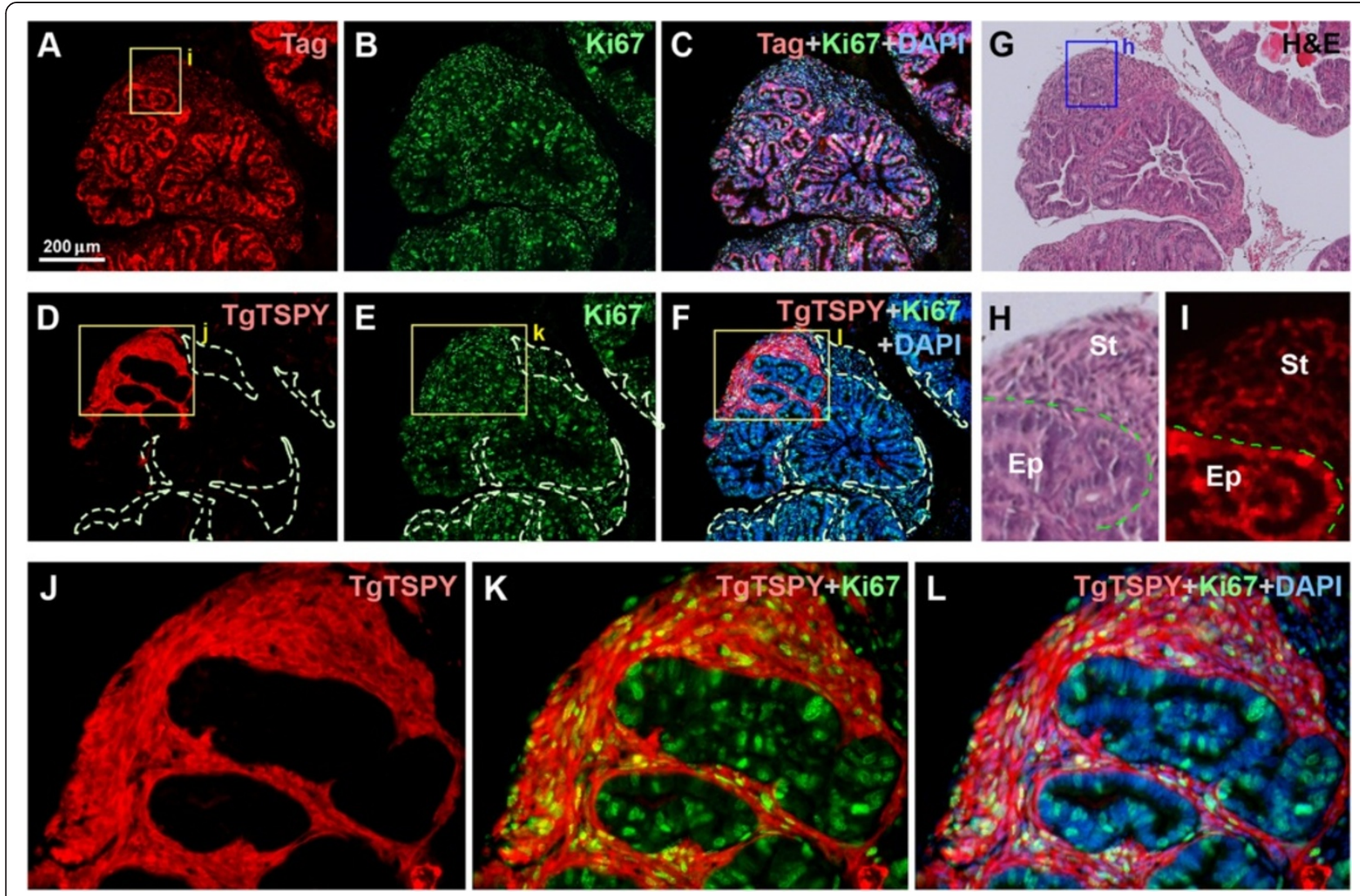

Figure 1 Expression of TSPY transgene in the prostates of TgTSPY9/LADY mice at 12 weeks of age. A-C, Double immunofluorescence staining of T-antigen (red) and Ki67 (green) in the prostate of TgTSPY9/LADY mouse at 12 weeks of age. DNA was visualized by DAPI staining (blue). C represents the merged image of T-antigen (red), Ki67 (green) and DNA (blue). D-F, Double immunofluorescence staining of the TSPY-transgene product (TgTSPY, red) and Ki67 (green) on the adjacent section of A-C. F represents the merged image of TgTSPY (red), Ki67 (green) and DNA (blue). TgTSPY-negative hypercellular stroma areas were circled by dot lines. G-H, H\&E staining of an adjacent section of $\mathbf{A}-\mathbf{C}$. $\mathbf{H}$ shows the highly magnified image of the boxed area in $\mathbf{G}$. Epithelial cells (Ep) and hypercellular stroma (St) were labeled. I is a highly magnified view of the boxed area in A, staining of T-antigen. T-antigen was expressed in both epithelial cells and stromal cells. J-L, Highly magnified views of TgTSPY (red) and Ki67 (green) for the boxed area in D-F respectively. $\mathbf{K}$ represents the merged view of TgTSPY (red) and Ki67 (green), and $\mathbf{L}$ represents the merged image of $\mathbf{K}$ plus DNA staining (blue). Scale bar $=200 \mu \mathrm{m}$ in A-G. Significant expression of TgTSPY was frequently detected in hypercellular stroma, developed in the prostate of TgTSPY9/LADY mice at this age.

at 14 weeks of age (Figure $4 \mathrm{E}-\mathrm{H})$. These observations suggest that, TSPY is differentially expressed in LADY transgenic mouse model of prostate cancer and clinical human prostate cancer.

\section{Discussion}

The role of the $\mathrm{Y}$ chromosome in prostatic oncogenesis has been debated numerous occasions, in which the gain or loss of this male-only chromosome has been reported [9-13]. The identification of TSPY as the gene for the gonadoblastoma locus on the $\mathrm{Y}$ chromosome has raised the possibility that this repeated proto-oncogene could participate in the oncogenic processes of human cancers, in which TSPY is inappropriately expressed. The present study represents an assessment of the TgTSPY9 as a model for evaluation of the response of the Y-located $T S P Y$-transgene to experimental oncogenesis. Human prostate cancer has been postulated to originate from prostate epithelial cells (either basal cells or luminal cells) [51-53] (Figure 5). TSPY is normally expressed in the spermatogonial cells and prophase I of the adult testis, but not in somatic cells. However, under oncogenic conditions, TSPY is activated in epithelial cells in the morphologically normal glands adjacent to cancer area, as well as in adenocarcinoma cells in prostate cancer $[27,28]$. Previously, we demonstrated that TSPY could exert pro-growth properties in enhancing protein synthesis, accelerating cell cycle progression, stimulating cyclin BCDK1 kinase activities, abbreviating $G_{2} / M$ transition, which potentially could abolish $\mathrm{G}_{2} / \mathrm{M}$ checkpoints and increasing chromosome nondisjunction and genomic instability $[29,30]$. Hence, TSPY activation in the premalignant epithelial cells, and tumorigenic cells could collectively promote prostatic carcinogenesis. However, no 

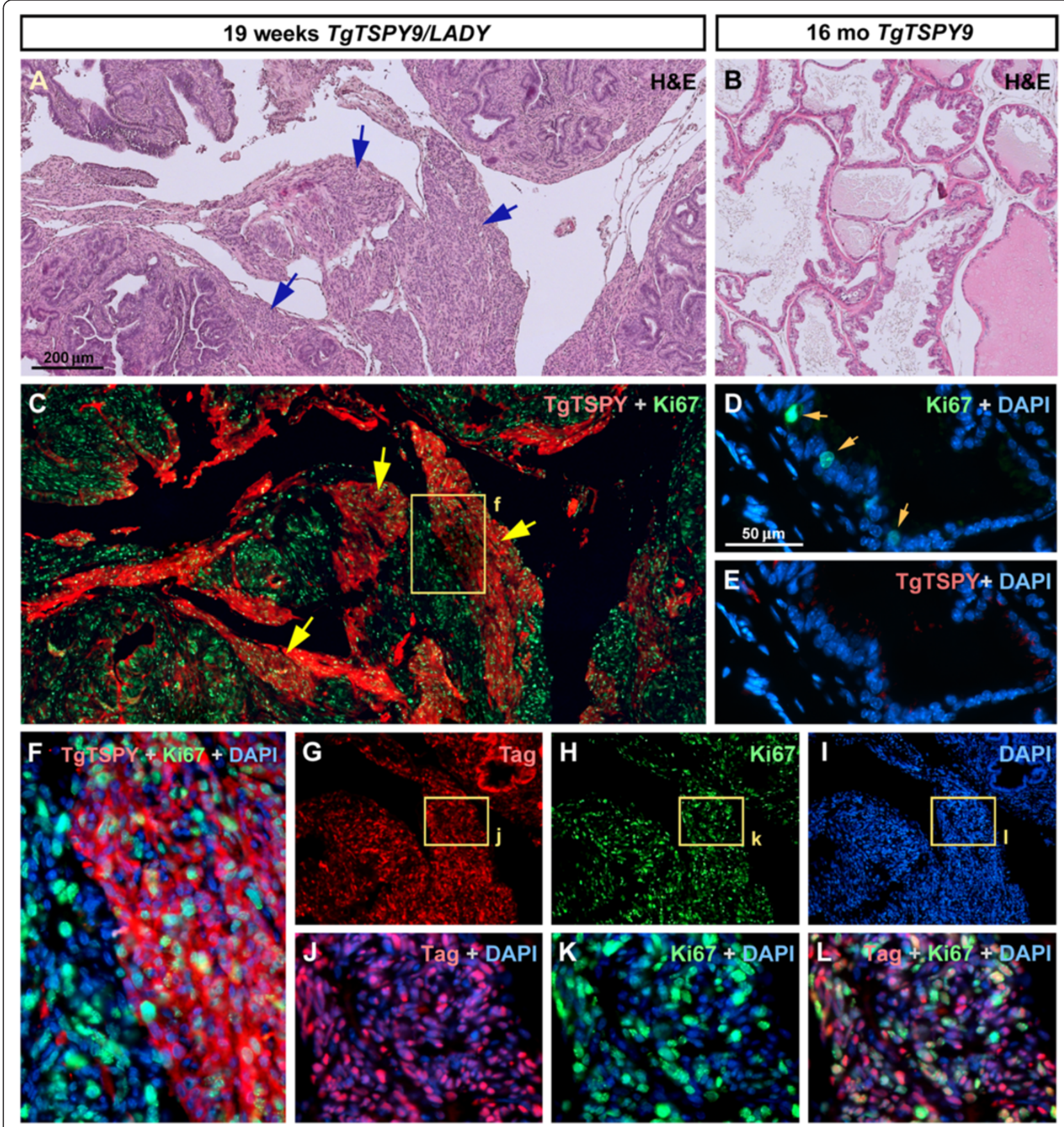

Figure 2 Expression of TSPY-transgene in the prostates of TgTSPY9/LADY mice at 19 weeks of age. A, Representative H\&E staining image of the sections of prostate from TgTSPY9/LADY mouse at age 19 weeks. Hypercellular stroma was further enlarged comparing with 12 weeks of age (arrows). B, H\&E stained image of the sections of prostate from TgTSPY9 mouse at 16 months of age. C, Double immunofluorescence staining of the TSPY-transgene product (TgTSPY, red) and Ki67 (green) in the adjacent section of $\mathbf{A}$. TgTSPY was significantly expressed in large part of hypercellular stroma. D-E, Double immunofluorescence staining of TgTSPY (red) and Ki67 (green) in the prostate from TgTSPY9 mouse at 16 month of age. D represents a merged image of Ki67 (green) and DNA (blue), and $\mathbf{E}$ represents a merged image of TgTSPY (red) and DNA (blue). $\mathbf{F}$ represents a highly magnified view of the boxed area in C, showing signals of TgTSPY (red), Ki67 (green) and DNA (blue). G-I, Double immunofluorescence staining of T-antigen (Tag) and Ki67 in the prostate from TgTSPY9/LADY mouse at age 19 weeks (adjacent section of C). DNA was visualized by DAPI staining (blue). J-L, Highly magnified views of boxed areas in G-I. J and $\mathbf{K}$ represents the merged images of Tag (red) and DNA (blue), or Ki67 (green) and DNA (blue), respectively. L represents the merged view of Tag (red), Ki67 (green) and DNA (blue). Scale bar $=200 \mu \mathrm{m}$ in A-C, G-I, and $50 \mu \mathrm{m}$ in D-E. Tag and Ki67 expressed closely in same cells of the prostate of TgTSPY9/LADY mouse at age 19 weeks. 

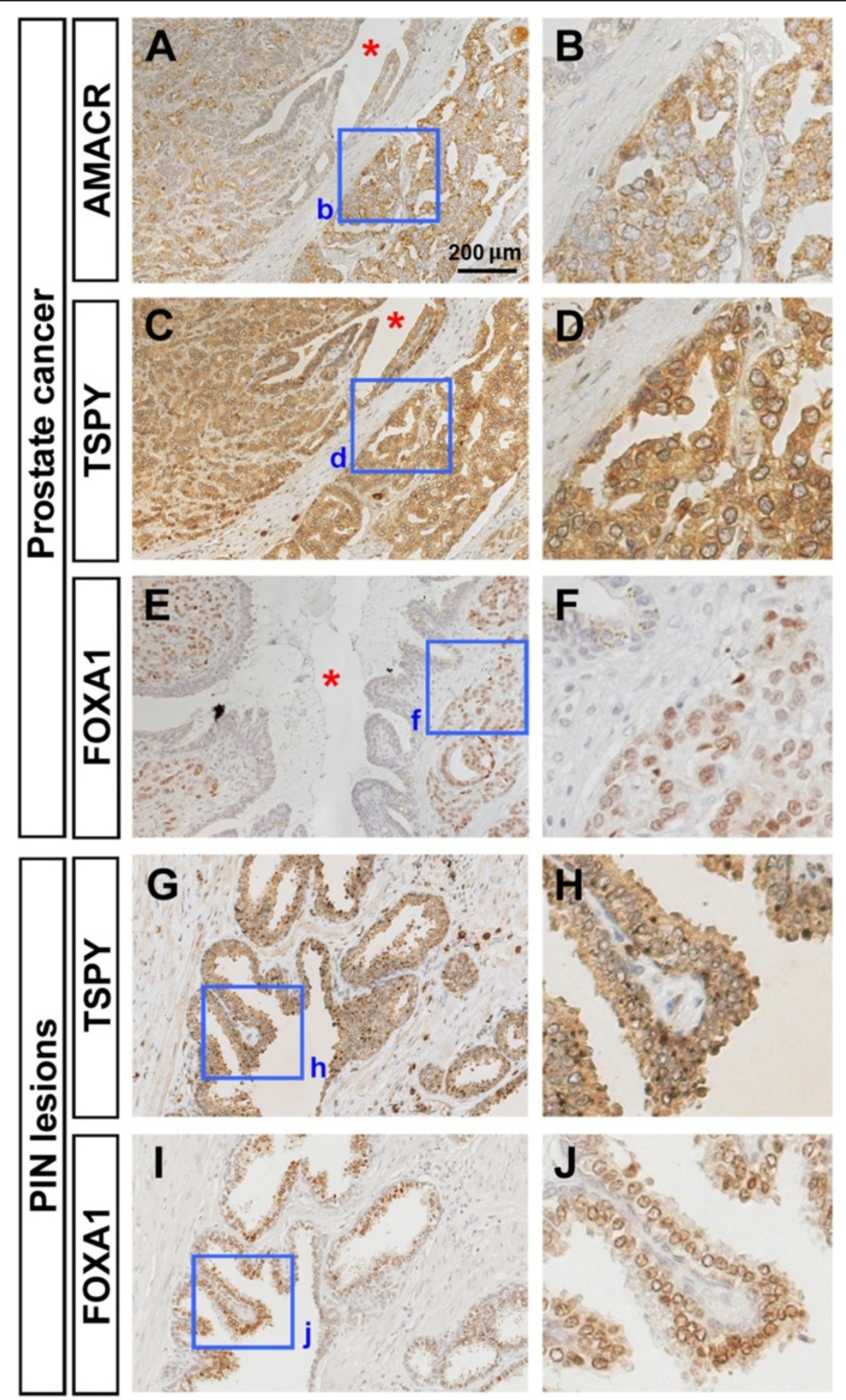

Figure 3 Immunohistochemical analysis of TSPY, FOXA1 and AMACR expression in human prostatic cancer specimens. A-B, Immunostaining of AMACR (brown) in prostatic adenocarcinoma. Nuclei were counterstained by hematoxylin (blue). C-D, Immunostaining of TSPY (brown) in prostatic adenocarcinoma (adjacent section of A). Significant TSPY staining was observed in cancer cells, but faint or negative staining in the surrounding stroma. E-F, Immunostaining of FOXA1 (brown) in prostatic adenocarcinoma (section close to $\mathbf{A}$ in the same specimen). Strong signal of FOXA1 expression was observed in nuclei of adenocarcinoma cells. Asterisks indicate the common duct among $\mathbf{A}, \mathbf{C}$ and $\mathbf{E}$. G-H, Immunostaining of TSPY (brown) in PIN lesions. I-J, Immunostaining of FOXA1 (brown) in PIN lesions (adjacent section of G). Both TSPY and FOXA1 were expressed in adenocarcinoma cells and epithelial cells in PIN lesions. B, D, F, H and $\mathbf{J}$ represent the highly magnified views of the boxed area in $\mathbf{A}, \mathbf{C}, \mathbf{E}, \mathbf{G}$ and $\mathbf{I}$, respectively. Scale bar $=200 \mu \mathrm{m}$ in $\mathbf{A}, \mathbf{C}, \mathbf{E}, \mathbf{G}$ and $\mathbf{I}$. 
significant difference was observed in the size of prostates and tumors between LADY and TgTSPY9/LADY mice in the present study (data not shown). Currently, the exact reason is uncertain. Activation of TSPY expression in the hyperplasia stroma could have an effect(s) on the evolution of the tumorigenic processes not associated with tumor size. Significantly, some studies suggest that the SV40-based transgenic models of oncogenesis have limitations, since the SV40 viral oncoprotein is not a likely etiologic agent for prostate cancer in humans and it has relatively intensive cellular effects [54], such that the mice, e.g. LADY mice, rapidly developed massive prostatic hyperplasia within a few months. Human primary prostate cancer, on the other hand, is slow growing in most cases $[55,56]$. We surmise that the effects of TSPY might not be readily noticeable in fast-growing tumor developed in the LADY mouse background. Mouse models that slowly develop prostatic tumor should be helpful in elucidating the role of TSPY in cancer development in vivo.

The activation of the Y-located TSPY-transgene in the prostate of the LADY model seems to validate the postulation that human TSPY gene on the Y chromosome could be dysregulated and activated under prostatic oncogenic conditions. The present observation that the TSPY-transgene is expressed in hypercellular stroma but not in mPIN lesions in the prostate of TgTSPY9/LADY mice is somewhat unexpected from the initial postulation. At present, the exact mechanism(s) contributing to such differential TSPY expression patterns between human prostate cancer and LADY tumor model is uncertain. It has been reported that the gene expression pattern is largely different between mouse prostate and human prostate [57]. In addition, prostatic epithelial cells and stromal cells express specific sets of genes different from each other during oncogenesis $[57,58]$. We postulate that a combination of species-specific and cell typespecific gene regulation mechanisms could be involved in the differential expression of TSPY between human clinical prostate cancer and TgTSPY9/LADY mouse prostatic tumor.

Human prostate cancer is postulated to originate from epithelial cells (either basal cells or luminal cells) of the prostate [51-53], however, numerous studies have clearly demonstrated that the stromal cells also play key roles to the overall carcinogenesis [6-8,59,60] (Figure 5). Hence interplay between epithelial and stromal cells could be important in human prostatic oncogenesis. In the LADY model of prostate cancer, the SV40 large T antigen is ubiquitously expressed in the epithelial and stromal cells of the prostate and might possibly exert its oncogenic actions in both cell types. Our results suggest the TSPY-transgene could be more susceptible for being activated from its tight Y chromosome regulation in stromal cells than epithelial cells in the prostates of the LADY mice. Since all TSPY-positive cells are stromal cells at later stages of the
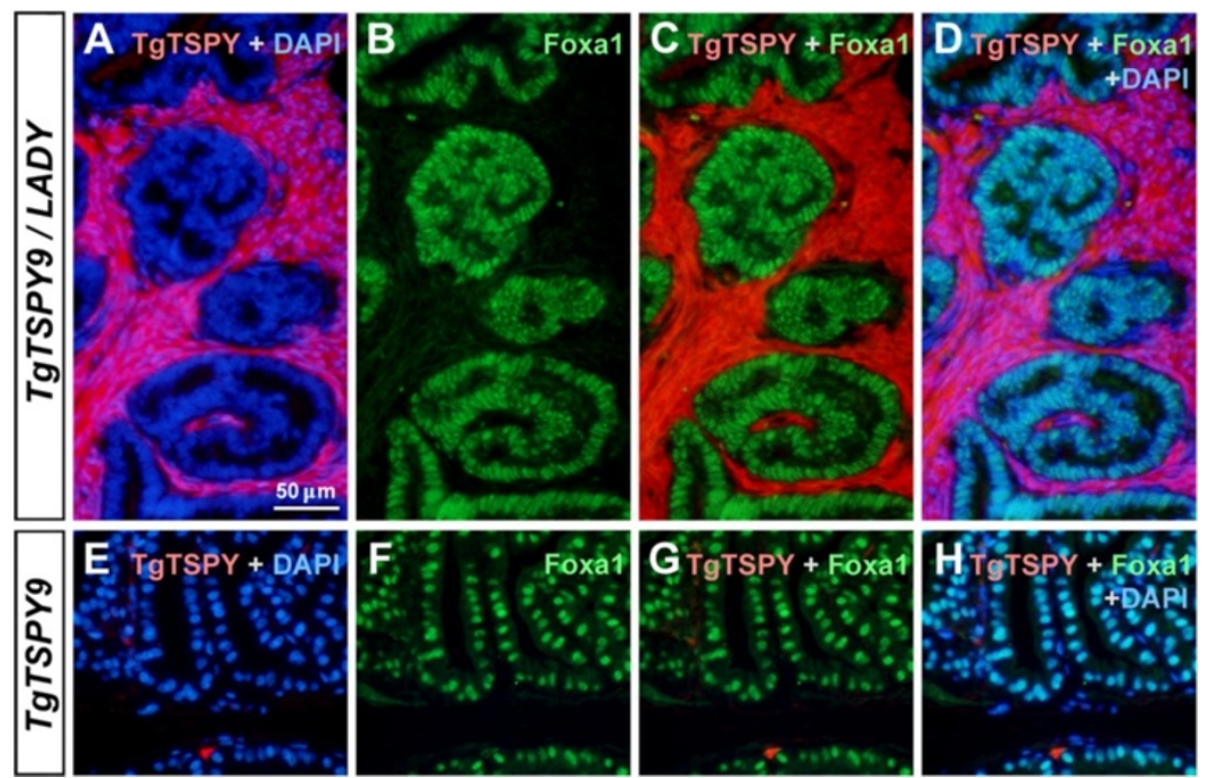

Figure 4 Expression of TSPY-transgene and Foxa1 in the prostates of TgTSPY9/LADY mice at 14 weeks of age. A-D, Double immunofluorescence staining of the TSPY-transgene product (TgTSPY, red) and Foxa1 (green) in the prostate of TgTSPY9/LADY mouse at 14 weeks of age. DNA was visualized by DAPI staining (blue). $\mathbf{C}$ represents the merged view of TgTSPY (red) and Foxa1 (green), and D represents the merged view including DNA (blue). Note that the expression of TgTSPY did not overlap with that of Foxa1. E-H, Double immunofluorescence staining of TgTSPY (red) and Foxa1 (green) in the prostate of singly transgenic TgTSPY9 mouse at 14 weeks of age. G represents the merged view of TgTSPY (red) and Foxa1 (green), and $\mathbf{H}$ represents the merged view including DNA (blue). Scale bar $=50 \mu \mathrm{m}$ in $\mathbf{A}-\mathbf{H}$. 


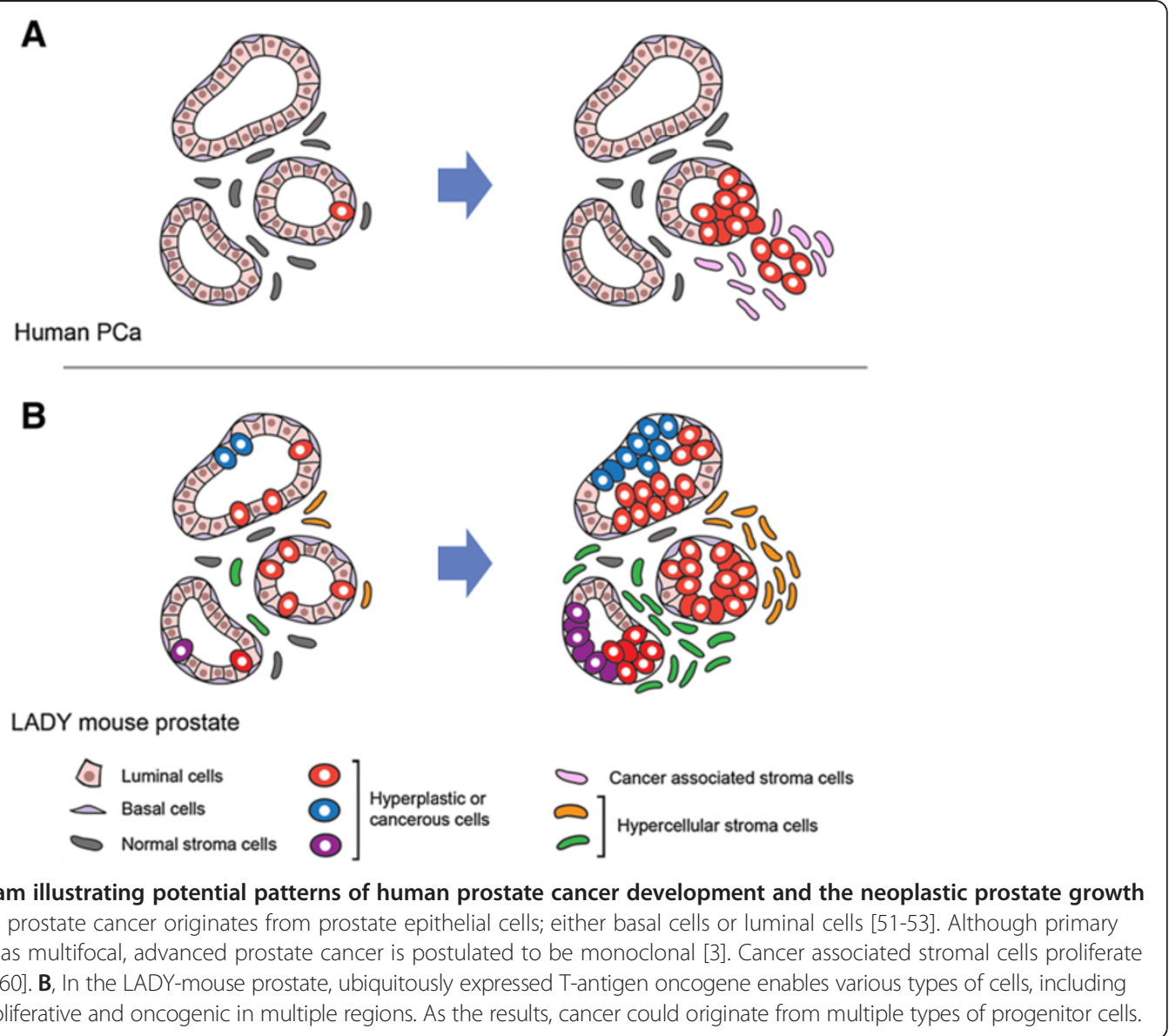

prostatic tumors, these TSPY-positive stromal cells could have a clonal origin. The fact that only clusters of stromal cells are positive for TSPY at all stages suggests heterogeneity in the tumorigenic processes in the LADY model of prostate cancer. The differential expression of the Y-located human TSPY gene between the LADY mouse model and clinical prostate cancer highlights a possible limitation(s) of current modeling of human prostate cancer in mice.

\section{Materials and methods \\ Animals}

Mice for the 12T-7f LPB-Tag (LADY) model of prostate cancer were obtained from the NCI-Mutant Mouse Repository (MD, USA), and were initially constructed and characterized by Matusik and colleagues [35]. TgTSPY9 transgenic mouse line, harboring multiple copies of $8.2 \mathrm{~kb}$ genomic fragment of human TSPY gene on its Ychromosome, was originally constructed by Drs. Stephanie Schubert and Jorge Schmidtke [43]. The genomic background of 12T-7f LADY mice and TgTSPY9 mice were CD-1 and NMRI respectively. Tissues were dissected from 12T-7f LADY $\times$ TgTSPY9 heterozygous F1 mice, and analyzed by immunohistochemical methods as described below.

All animals were maintained as breeding colonies at the Animal Care Facility of San Francisco VA Medical Center. The Institutional Animal Care and Use Committee of the VA Medical Center approved all experimental procedures in accordance with the NIH Guide for Care and Use of Laboratory Animals.

\section{Human prostate specimens}

The clinical prostate cancer specimens were derived from de-identified archival pathological preparations of the Department of Urology, Hirosaki University, Japan, and analyzed as previously described [28]. The analysis of these specimens was performed under approved protocols from the respective Institutional Committees on Human Research, VA Medical Center, San Francisco and Hirosaki University, Aomori, Japan.

\section{Immunofluorescence and immunohistochemical analysis}

The tissues were fixed in $4 \%$ paraformaldehyde-PBS solution and embedded in paraffin by standard protocol. Immunohistological and immunofluorescence analyses of 
tissue sections were performed as described previously [61], using anti-SV40 T-antigen mouse antibody (1:80, Santa Cruz Biotechnology, Inc., Santa Cruz, CA, USA), anti-TSPY rabbit serum (1:400), anti-TSPY mouse monoclonal antibody (1:3000, clone-7), anti-Ki67 rabbit IgG (1:100, Neomarkers/Thermo scientific, Kalamazoo, MI, USA), anti-AMACR rabbit antibody (1:50, Abcam Inc., Cambridge, MA, USA), anti-FOXA1 rabbit antibody (1:200, Abcam Inc). The immunoreactive sites were visualized with Super Picture Polymer Detection kit (ZYMED/ Invitrogen, Carlsbad, CA, USA) or VECTASTAIN Elite ABC kit (Vector laboratories, Burlingame, CA, USA) using 3, 3'-Diaminobenzidine (DAB). For immunofluorescence, the immunoreactive signals were detected by Alexa Fluor 586 (red)-conjugated anti-mouse IgG and Alexa Fluor 488 (green)-conjugated anti-rabbit IgG (Molecular Probes/ Invitrogen, Carlsbad, CA, USA) as secondary antibodies. DNA was visualized by staining with 4', 6-Diamidine,2 '-phenylindole dihydrochloride (DAPI, Roche Applied Science, Indianapolis, IN, USA). Fluorescence was examined with an Axiophoto fluorescence microscope (Carl Zeiss MicroImaging, Thronwood, NY, USA) and recorded with a LEI-750 digital imaging system (Leica Microsystmes, Bannockburn, IL, USA).

\section{Competing interests}

The authors declare that they have no competing interests.

\section{Authors' contributions}

TK and YFCL conceived the concept and designed the experiments. TK performed the experiments. SS and SM constructed the TgTSPY9 transgenic mouse line and $\mathrm{SH}$ and $\mathrm{CO}$ provided the human prostate cancer specimens. TK and YFCL co-wrote the manuscript. All authors read and approved the final manuscript.

\section{Acknowledgement}

This work is supported by a VA merit-reviewed grant to YFCL and YFCL is a Career Research Scientist of the Department of Veterans Affairs.

\section{Author details \\ ${ }^{1}$ Laboratory of Cell and Developmental Genetics, Department of Medicine, VA Medical Center \& Institute for Human Genetics, University of California, 4150 Clement Street, San Francisco, CA, USA. ${ }^{2}$ Institute of Human Genetics, Hannover Medical School, D-30625 Hannover, Germany. ${ }^{3}$ Department of Urology, Hirosaki University Graduate School of Medicine, Hirosaki 036-8562, Japan.}

Received: 21 November 2013 Accepted: 17 December 2013

Published: 17 February 2014

\section{References}

1. Report of National Cancer Institute, United States. http://www.cancer.gov/ cancertopics/types/prostate.

2. Nelson WG, De Marzo AM, Isaacs WB: Prostate cancer. N Engl J Med 2003, 349:366-381.

3. Shen MM, Abate-Shen C: Molecular genetics of prostate cancer: new prospects for old challenges. Genes Dev 2010, 24:1967-2000.

4. Yu YP, Landsittel D, Jing L, Nelson J, Ren B, Liu L, McDonald C, Thomas R, Dhir R, Finkelstein S, Michalopoulos G, Becich M, Luo JH: Gene expression alterations in prostate cancer predicting tumor aggression and preceding development of malignancy. J Clin Oncol 2004, 22:2790-2799.

5. Stanbrough M, Bubley GJ, Ross K, Golub TR, Rubin MA, Penning TM, Febbo PG, Balk SP: Increased expression of genes converting adrenal androgens to testosterone in androgen-independent prostate cancer. Cancer Res 2006, $66: 2815-2825$
6. Cunha GR, Hayward SW, Wang YZ, Ricke WA: Role of the stromal microenvironment in carcinogenesis of the prostate. Int J Cancer 2003, 107:1-10.

7. Cunha GR, Hayward SW, Wang YZ: Role of stroma in carcinogenesis of the prostate. Differentiation 2002, 70:473-485.

8. Hayward SW, Rosen MA, Cunha GR: Stromal-epithelial interactions in the normal and neoplastic prostate. Br J Urol 1997, 79(Suppl 2):18-26.

9. Vijayakumar S, Garcia D, Hensel CH, Banerjee M, Bracht T, Xiang R, Kagan J, Naylor SL: The human Y chromosome suppresses the tumorigenicity of PC-3, a human prostate cancer cell line, in athymic nude mice. Genes Chromosomes Cancer 2005, 44:365-372.

10. Vijayakumar S, Hall DC, Reveles XT, Troyer DA, Thompson IM, Garcia D, Xiang R, Leach RJ, Johnson-Pais TL, Naylor SL: Detection of recurrent copy number loss at Yp11.2 involving TSPY gene cluster in prostate cancer using array-based comparative genomic hybridization. Cancer Res 2006, 66:4055-4064.

11. Jordan JJ, Hanlon AL, Al-Saleem TI, Greenberg RE, Tricoli JV: Loss of the short arm of the $\mathrm{Y}$ chromosome in human prostate carcinoma. Cancer Genet Cytogenet 2001, 124:122-126.

12. Kuroda N, Shiotsu T, Hes O, Michal M, Shuin T, Lee GH: Acquired cystic disease-associated renal cell carcinoma with gain of chromosomes 3, 7, and 16, gain of chromosome $\mathrm{X}$, and loss of chromosome $\mathrm{Y}$. Med Mol Morphol 2010, 43:231-234.

13. Tricoli JV: $Y$ chromosome enumeration in touch preparations from 42 prostate tumors by interphase fluorescence in situ hybridization analysis. Cancer Genet Cytogenet 1999, 111:1-6.

14. Hood L, Rowen L: The human genome project: big science transforms biology and medicine. Genome Med 2013, 5:79.

15. Skaletsky H, Kuroda-Kawaguchi T, Minx PJ, Cordum HS, Hillier L, Brown LG, Repping S, Pyntikova T, Ali J, Bieri T, Chinwalla A, Delehaunty A, Delehaunty K, Du H, Fewell G, Fulton L, Fulton R, Graves T, Hou SF, Latrielle P, Leonard S, Mardis E, Maupin R, McPherson J, Miner T, Nash W, Nguyen C, Ozersky P, Pepin K, Rock S, et al: The male-specific region of the human $Y$ chromosome is a mosaic of discrete sequence classes. Nature 2003, 423:825-837.

16. Lau YF, Zhang J: Expression analysis of thirty one $\mathrm{Y}$ chromosome genes in human prostate cancer. Mol Carcinog 2000, 27:308-321.

17. Tsuchiya K, Reijo R, Page DC, Disteche CM: Gonadoblastoma: molecular definition of the susceptibility region on the Y chromosome. Am J Hum Genet 1995, 57:1400-1407.

18. Salo P, Kaariainen H, Petrovic V, Peltomaki P, Page DC, de la Chapelle A: Molecular mapping of the putative gonadoblastoma locus on the $Y$ chromosome. Genes Chromosomes Cancer 1995, 14:210-214.

19. Page DC: Hypothesis: a Y-chromosomal gene causes gonadoblastoma in dysgenetic gonads. Development 1987, 101(Suppl):151-155.

20. Lau Y, Chou P, lezzoni J, Alonzo J, Komuves L: Expression of a candidate gene for the gonadoblastoma locus in gonadoblastoma and testicular seminoma. Cytogenet Cell Genet 2000, 91:160-164.

21. Kersemaekers AM, Honecker F, Stoop H, Cools M, Molier M, Wolffenbuttel K, Bokemeyer C, Li Y, Lau YF, Oosterhuis JW, Looijenga LH: Identification of germ cells at risk for neoplastic transformation in gonadoblastoma: an immunohistochemical study for OCT3/4 and TSPY. Hum Pathol 2005, 36:512-521.

22. Arnemann J, Epplen JT, Cooke HJ, Sauermann U, Engel W, Schmidtke J: A human Y-chromosomal DNA sequence expressed in testicular tissue. Nucleic Acids Res 1987, 15:8713-8724.

23. Zhang JS, Yang-Feng TL, Muller U, Mohandas TK, de Jong PJ, Lau YF: Molecular isolation and characterization of an expressed gene from the human Y chromosome. Hum Mol Genet 1992, 1:717-726.

24. Kido T, Lau YF: A Cre gene directed by a human TSPY promoter is specific for germ cells and neurons. Genesis 2005, 42:263-275.

25. Gallagher WM, Bergin OE, Rafferty M, Kelly ZD, Nolan IM, Fox EJ, Culhane AC, McArdle L, Fraga MF, Hughes L, Currid CA, O'Mahony F, Byrne A Murphy AA, Moss C, McDonnell S, Stallings RL, Plumb JA, Esteller M, Brown R, Dervan PA, Easty DJ: Multiple markers for melanoma progression regulated by DNA methylation: insights from transcriptomic studies. Carcinogenesis 2005, 26:1856-1867.

26. Yin YH, Li YY, Qiao H, Wang HC, Yang XA, Zhang HG, Pang XW, Zhang $Y$, Chen WF: TSPY is a cancer testis antigen expressed in human hepatocellular carcinoma. Br J Cancer 2005, 93:458-463.

27. Lau YF, Lau HW, Komuves LG: Expression pattern of a gonadoblastoma candidate gene suggests a role of the $Y$ chromosome in prostate cancer. Cytogenet Genome Res 2003, 101:250-260. 
28. Kido T, Hatakeyama S, Ohyama C, Lau YF: Expression of the Y-Encoded TSPY is Associated with Progression of Prostate Cancer. Genes 2010, 1:283-293.

29. Li Y, Lau YF: TSPY and its X-encoded homologue interact with cyclin B but exert contrasting functions on cyclin-dependent kinase 1 activities. Oncogene 2008, 27:6141-6150.

30. Oram SW, Liu XX, Lee TL, Chan WY, Lau YF: TSPY potentiates cell proliferation and tumorigenesis by promoting cell cycle progression in HeLa and NIH3T3 cells. BMC Cancer 2006, 6:154.

31. Kido T, Lau YF: The human Y-encoded testis-specific protein interacts functionally with eukaryotic translation elongation factor eEF1A, a putative oncoprotein. Int J Cancer 2008, 123:1573-1585.

32. Ittmann M, Huang J, Radaelli E, Martin P, Signoretti S, Sullivan R, Simons BW, Ward JM, Robinson BD, Chu GC, Loda M, Thomas G, Borowsky A, Cardiff RD: Animal models of human prostate cancer: the consensus report of the New York meeting of the Mouse Models of Human Cancers Consortium Prostate Pathology Committee. Cancer Res 2013, 73:2718-2736.

33. Jeet $V$, Russell PJ, Khatri A: Modeling prostate cancer: a perspective on transgenic mouse models. Cancer Metastasis Rev 2010, 29:123-142.

34. Shappell SB, Thomas GV, Roberts RL, Herbert R, Ittmann MM, Rubin MA, Humphrey PA, Sundberg JP, Rozengurt N, Barrios R, Ward JM, Cardiff RD: Prostate pathology of genetically engineered mice: definitions and classification. The consensus report from the Bar Harbor meeting of the Mouse Models of Human Cancer Consortium Prostate Pathology Committee. Cancer Res 2004, 64:2270--2305.

35. Kasper S, Sheppard PC, Yan Y, Pettigrew N, Borowsky AD, Prins GS, Dodd JG, Duckworth ML, Matusik RJ: Development, progression, and androgen-dependence of prostate tumors in probasin-large $T$ antigen transgenic mice: a model for prostate cancer. Lab Invest 1998, 78(6):i-xV.

36. Ishii K, Shappell SB, Matusik RJ, Hayward SW: Use of tissue recombination to predict phenotypes of transgenic mouse models of prostate carcinoma. Lab Invest 2005, 85:1086-1103.

37. Tu WH, Thomas TZ, Masumori N, Bhowmick NA, Gorska AE, Shyr Y, Kasper S, Case T, Roberts RL, Shappell SB, Moses HL, Matusik RJ: The loss of TGF-beta signaling promotes prostate cancer metastasis. Neoplasia 2003, 5:267-277.

38. Vogel T, Dechend F, Manz E, Jung C, Jakubiczka S, Fehr S, Schmidtke J, Schnieders F: Organization and expression of bovine TSPY. Mamm Genome 1997, 8:491-496.

39. Hughes JF, Skaletsky H, Pyntikova T, Graves TA, van Daalen SK, Minx PJ, Fulton RS, McGrath SD, Locke DP, Friedman C, Trask BJ, Mardis ER, Warren WC, Repping S, Rozen S, Wilson RK, Page DC: Chimpanzee and human Y chromosomes are remarkably divergent in structure and gene content. Nature 2010, 463:536-539.

40. Mazeyrat S, Mitchell MJ: Rodent Y chromosome TSPY gene is functional in rat and non-functional in mouse. Hum Mol Genet 1998, 7:557-562.

41. Schubert S, Dechend F, Skawran B, Kunze B, Winking H, Weile C, Romer I, Hemberger M, Fundele R, Sharma T, Schmidtke J: Silencing of the Y-chromosomal gene tspy during murine evolution. Mamm Genome 2000, 11:288-291.

42. Kido T, Schubert S, Schmidtke J, Chris Lau YF: Expression of the human TSPY gene in the brains of transgenic mice suggests a potential role of this $Y$ chromosome gene in neural functions. J Genet Genomics 2011, 38:181-191.

43. Schubert S, Skawran B, Dechend F, Nayernia K, Meinhardt A, Nanda I, Schmid M, Engel W, Schmidtke J: Generation and characterization of a transgenic mouse with a functional human TSPY. Biol Reprod 2003, 69:968-975.

44. Lau YF, Li Y, Kido T: Role of the Y-located putative gonadoblastoma gene in human spermatogenesis. Syst Biol Reprod Med 2011, 57:27-34.

45. Cho HJ, Seiberg M, Georgoff I, Teresky AK, Marks JR, Levine AJ: Impact of the genetic background of transgenic mice upon the formation and timing of choroid plexus papillomas. J Neurosci Res 1989, 24:115-122.

46. Attardi LD, Donehower LA: Probing p53 biological functions through the use of genetically engineered mouse models. Mutat Res 2005, 576:4-21.

47. Freeman D, Lesche R, Kertesz N, Wang S, Li G, Gao J, Groszer M, Martinez-Diaz H, Rozengurt N, Thomas G, Liu X, Wu H: Genetic background controls tumor development in PTEN-deficient mice. Cancer Res 2006, 66:6492-6496.

48. Sahu B, Laakso M, Ovaska K, Mirtti T, Lundin J, Rannikko A, Sankila A, Turunen JP, Lundin M, Konsti J, Vesterinen T, Nordling S, Kallioniemi O, Hautaniemi S, Jänne OA: Dual role of FoxA1 in androgen receptor binding to chromatin, androgen signalling and prostate cancer. EMBO J 2011, 30:3962-3976
49. Mirosevich J, Gao N, Gupta A, Shappell SB, Jove R, Matusik RJ: Expression and role of Foxa proteins in prostate cancer. Prostate 2006, 66:1013-1028.

50. Chiaverotti T, Couto SS, Donjacour A, Mao JH, Nagase H, Cardiff RD, Cunha GR, Balmain A: Dissociation of epithelial and neuroendocrine carcinoma lineages in the transgenic adenocarcinoma of mouse prostate model of prostate cancer. Am J Pathol 2008, 172:236-246.

51. Xin L: Cells of origin for cancer: an updated view from prostate cancer. Oncogene 2013, 32:3655-3663.

52. Australian Prostate Cancer B, Taylor RA, Toivanen R, Frydenberg M, Pedersen J, Harewood L, Collins AT, Maitland NJ, Risbridger GP: Human epithelial basa cells are cells of origin of prostate cancer, independent of CD133 status. Stem Cells 2012, 30:1087-1096.

53. Wang ZA, Mitrofanova A, Bergren SK, Abate-Shen C, Cardiff RD, Califano A, Shen MM: Lineage analysis of basal epithelial cells reveals their unexpected plasticity and supports a cell-of-origin model for prostate cancer heterogeneity. Nat Cell Bio/ 2013, 15:274-283.

54. Sharma P, Schreiber-Agus N: Mouse models of prostate cancer. Oncogene 1999, 18:5349-5355.

55. Friberg S, Mattson S: On the growth rates of human malignant tumors: implications for medical decision making. J Surg Oncol 1997, 65:284-297.

56. Griffiths K, Prezioso D, Turkes A, Denis LJ: The prevention of prostate cancer. Recent Results Cancer Res 2007, 175:33-63.

57. Berquin IM, Min Y, Wu R, Wu H, Chen YQ: Expression signature of the mouse prostate. J Biol Chem 2005, 280:36442-36451.

58. Gregg JL, Brown KE, Mintz EM, Piontkivska H, Fraizer GC: Analysis of gene expression in prostate cancer epithelial and interstitial stromal cells using laser capture microdissection. BMC Cancer 2010, 10:165.

59. Ricke EA, Williams K, Lee YF, Couto S, Wang Y, Hayward SW, Cunha GR, Ricke WA: Androgen hormone action in prostatic carcinogenesis: stromal androgen receptors mediate prostate cancer progression, malignant transformation and metastasis. Carcinogenesis 2012, 33:1391-1398.

60. Strand DW, Hayward SW: Modeling stromal-epithelial interactions in disease progression. Discov Med 2010, 9:504-511.

61. Kido T, Lau YF: The rat Tspy is preferentially expressed in elongated spermatids and interacts with the core histones. Biochem Biophys Res Commun 2006, 350:56-67.

doi:10.1186/2045-3701-4-9

Cite this article as: Kido et al:: Expression of a Y-located human proto-oncogene TSPY in a transgenic mouse model of prostate cancer. Cell \& Bioscience 2014 4:9.

\section{Submit your next manuscript to BioMed Central and take full advantage of:}

- Convenient online submission

- Thorough peer review

- No space constraints or color figure charges

- Immediate publication on acceptance

- Inclusion in PubMed, CAS, Scopus and Google Scholar

- Research which is freely available for redistribution

Submit your manuscript at www.biomedcentral.com/submit
C) Biomed Central 